\title{
Long-term outcomes and prosthesis performance after transcatheter aortic valve replacement: results of self-expandable and balloon-expandable transcatheter heart valves
}

\author{
Giuseppe Tarantini ${ }^{1}$, Paola A. M. Purita ${ }^{1}$, Augusto D’Onofrio ${ }^{1}$, Chiara Fraccaro ${ }^{1}$, Anna Chiara Frigo ${ }^{1}$, \\ Gianpiero D'Amico ${ }^{1}$, Luca Nai Fovino ${ }^{1}$, Marta Martin ${ }^{1}$, Francesco Cardaioli ${ }^{1}$, Mostafa R. A. Badawy ${ }^{2}$, \\ Massimo Napodano ${ }^{1}$, Gino Gerosa ${ }^{1}$, Sabino Iliceto ${ }^{1}$ \\ ${ }^{1}$ Department of Cardiac, Thoracic and Vascular Sciences, University of Padua Medical School, Padua, Italy; ${ }^{2}$ Faculty of Medicine, Minia University, \\ Minya, Egypt \\ Correspondence to: Giuseppe Tarantini, MD, PhD, FESC. Cardiology Unit, Department of Cardiac, Thoracic and Vascular Sciences, University of \\ Padua Medical School, Via Giustiniani, 2, 35128 Padova, Italy. Email: giuseppe.tarantini.1@gmail.com.
}

\begin{abstract}
Background: Data on transcatheter aortic valve replacement (TAVR) long-term clinical outcomes and hemodynamic performance of the self-expandable CoreValve (CV) and the balloon-expandable Edwards SAPIEN XT (ES) (Edwards Lifesciences, Irvine, California, USA) transcatheter heart valves (THV) are limited. Therefore, this study aimed to compare long-term clinical outcome data and hemodynamic performance of TAVR with either CV or ES.

Methods: We reviewed prospectively collected data of 171 patients treated with TAVR for severe aortic stenosis (AS) at our center between June 2007 and December 2010, with last follow-up contact in 2016.

Results: Out of 171 patients treated with TAVR at our Institution, 87 received a CV and 84 an ES THV. Mean age was 81 [78-85] years, and mean Society of Thoracic Surgeons (STS) score was 7.5\% (4.5-13.9\%). Hemodynamic success by Valve Academic Research Consortium (VARC) definition was 97.1\%. Mean trans-prosthetic gradient remained low and stable during follow-up in both groups (at 5-year 9.2 \pm 6.4 versus $12.7 \pm 5.1 \mathrm{mmHg}, \mathrm{P}=0.10)$. Late prosthesis failure occurred in 4 cases $(2.4 \%)$. Thirty-day mortality was $4.7 \%$, and estimated survival rates by Kaplan-Meyer after 1, 5 and 8 years were $87.6 \%, 44.9 \%$, and $24.5 \%$, respectively, without difference between THV groups. Rates of cardiovascular death, stroke, myocardial infarction (MI) and congestive heart failure (CHF) were also similar with CV and ES at long-term followup. History of $\mathrm{CHF}$, pre-existent severe mitral regurgitation, paravalvular leak grade $\geq 2+$, and chronic obstructive pulmonary disease were independent predictors of late mortality at multivariable analysis.

Conclusions: Clinical and hemodynamic outcomes of patients treated by self-expandable CV or balloonexpandable ES THV were favorable and similar throughout long-term follow-up, with a rate of prosthesis failure of less than $3 \%$.
\end{abstract}

Keywords: Aortic stenosis (AS); transcatheter aortic valve implantation; long-term outcome; durability

Submitted Jul 19, 2017. Accepted for publication Aug 03, 2017.

doi: 10.21037/acs.2017.08.02

View this article at: http://dx.doi.org/10.21037/acs.2017.08.02

\section{Introduction}

Transcatheter aortic valve replacement (TAVR) has become the standard of care for inoperable and high surgical risk patients affected by symptomatic severe aortic stenosis (AS) $(1,2)$. Recent studies also suggest favorable results with transfemoral (TF) TAVR compared to conventional surgery in patients at intermediate risk, both for self-expandable and balloon-expandable transcatheter heart valves (THV) (3-6). Notwithstanding, one of the main concerns regarding the application of TAVR to lower risk and younger patients 
is the paucity of long-term data on outcomes and prosthesis durability (7-12). Moreover, there are no studies that have compared the long-term hemodynamic performance of the self-expandable CoreValve (CV) and the balloon-expandable Edwards SAPIEN XT (ES) (Edwards Lifesciences, Irvine, California, USA) THV. Accordingly, we analyzed longterm outcomes and prosthesis performance in patients undergoing TAVR at our center with either CV or ES.

\section{Methods}

\section{Study population}

We performed a retrospective analysis of the Padua University REVALVing Experience (PUREVALVE) registry, in which data on all patients undergoing TAVR at our Institution since June 2007 was prospectively collected (13-15). Our study focused on 171 consecutive patients treated between June 2007 and December 2010, who were therefore eligible at least for a 5 -year followup. All patients were affected by severe symptomatic AS and were considered suitable for TAVR according to current guidelines $(16,17)$. Surgical risk was calculated using the logistic EuroSCORE and the Society of Thoracic Surgeons (STS) score $(18,19)$. Demographic, clinical, echocardiographic and hemodynamic variables prior to TAVR were collected as previously reported (13-15). The study cohort complies with the Declaration of Helsinki and was approved by the local Ethics Committees, and all patients provided informed written consent before the procedure.

\section{TAVR procedure}

TAVR was performed using either the self-expandable CV Revalving System (Medtronic Minneapolis, Minnesota, USA) through the trans-femoral (TF) or trans-subclavian (TSub) approach, or the balloon-expandable ES through the TF or transapical (TA) approach. At the beginning of our TAVR program, the CV was the only THV available on site, while the ES was first introduced in our center in March 2009. The TF approach was used as the first choice, whenever possible. After TAVR, patients were treated with aspirin and clopidogrel for at least 3 months, and then with single antiplatelet therapy afterwards. When oral anticoagulation was indicated, patients were treated with a vitamin $\mathrm{K}$ antagonist and only one antiplatelet agent.

\section{Endpoints}

Procedural outcomes and follow-up events were classified according to Valve Academic Research Consortium (VARC) 2 definitions (20). Follow-up was conducted through clinical visits or telephone interview with the patient or the general practitioner, and scheduled at 1 and 12 months and yearly thereafter. Clinical endpoints were all-cause mortality, cardiovascular mortality, changes in the New York Heart Association (NYHA) functional class, rehospitalization due to congestive heart failure (CHF), stroke, and acute myocardial infarction (MI). Transthoracic echocardiographic examinations were systematically performed at baseline, $48 \mathrm{~h}$ after TAVR, and at each follow-up time point to evaluate prosthesis performance [trans-prosthetic gradient, effective orifice area and aortic regurgitation (AR)] as well as global morphological and functional measurements. The severity of AR was graded from 0 to 4 using an integrative approach as recommended by guidelines $(21,22)$. Late prosthesis failure was defined as mean aortic valve gradient $\geq 20 \mathrm{mmHg}$, effective orifice area $\leq 0.9-1.1 \mathrm{~cm}^{2}$ and/or Doppler velocity index $<0.35 \mathrm{~m} / \mathrm{s}$ and/or moderate or severe prosthetic valve regurgitation (20); the presence of leaflets thrombosis or valve endocarditis was excluded by computed tomography (CT) scan or autopsy.

\section{Statistical analysis}

Quantitative variables were analyzed descriptively, reporting mean \pm standard deviation $(\mathrm{SD})$ in case of normal distribution, median and $25^{\text {th }}$ to $75^{\text {th }}$ percentile [interquartile range (IQR)] otherwise. The CV and ES group were compared with Student's $t$-test or Wilcoxon rank sum test, as appropriate. Categorical variables were reported as numbers and percentages and compared between $\mathrm{CV}$ and ES groups using Chi-square or Fisher's exact tests, as appropriate. Survival analysis was conducted with the Kaplan-Meier method. Cox regression was used to identify univariate predictors of events from the major baseline and procedural characteristics. Variables with $\mathrm{P}<0.15$ at the univariate analysis were subsequently considered in a multivariable Cox regression model to identify independent predictors of events. Results of the Cox regression were reported as hazard ratio (HR), 95\% confidence interval (CI) and $\mathrm{P}$ values. Statistical analysis was conducted with SAS version 9.4 (SAS Institute Inc., Cary, NC, USA) for Windows. 


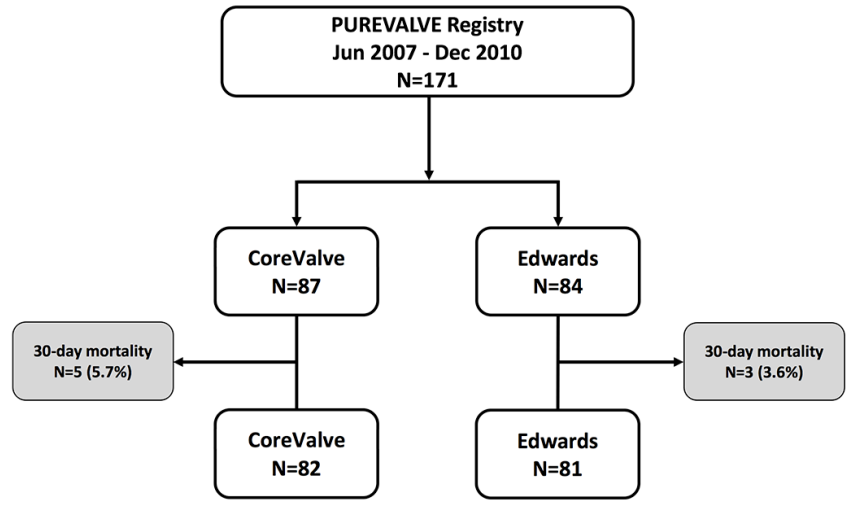

Figure 1 Patients flow diagram. This graph represents the flow diagram of our study population.

\section{Results}

Out of 171 patients treated by TAVR for severe symptomatic AS at our Institution between June 2007 and December 2010, 87 received a CV and 84 underwent an ES THV (Figure 1). Baseline demographic, clinical, and echocardiographic characteristics are summarized in Tables 1 and 2. Mean age was 81 [78-85] years, mean logistic EuroSCORE and STS were $17.8 \%$ and $7.5 \%$, respectively. The CV group had a higher rate of previous $\mathrm{MI}$ and worse left ventricular function compared to the ES group. The majority of patients were in NYHA functional class III or IV at baseline. Procedural characteristics are shown in Table 3. Hemodynamic and device success were high and similar between groups, with an overall intra-procedural mortality of $1.8 \%$. Post-dilatation was performed more frequently for $\mathrm{CV}$ than $\mathrm{ES}(31.0 \%$ vs. $3.6 \%, \mathrm{P}<0.001)$. The rate of permanent pacemaker (PPM) implantation was higher in the $\mathrm{CV}$ than in the ES group (37.9\% vs. $5.9 \%, \mathrm{P}>0.001)$.

\section{Early and late clinical outcomes}

Median follow-up in the overall population was 4.4 years (13 days-8 years), with a 94\% compliance with follow-up. In-hospital and 30-day outcomes are reported in Table 4. All-cause 30-day mortality was $4.7 \%$, without significant differences between groups $(5.8 \%$ vs. $3.6 \%, \mathrm{P}=0.72)$. Clinical efficacy at 1 year was higher in ES compared to the $\mathrm{CV}$ group (Figure $2 A$ ), mostly because of the lower rate of paravalvular leak (PVL) $\geq 2+$ (Table 5). At 5 years, no difference between groups was observed in terms of all-cause death, cardiovascular-death, stroke, MI and CHF (Figure 2B). As shown in Figure 3, total and cardiovascular survival rate were similar between groups at 7 years. At multivariable analysis, presence of a PVL $\geq 2+$, history of previous CHF, severe pre-existing mitral regurgitation and chronic obstructive pulmonary disease were independently associated with late mortality (Table 6). A significant and sustained improvement in NYHA functional class was observed in both valve groups (Figure 4). Restricting the analysis beyond 2009 (ES introduced), we failed to find differences in outcome between the two bioprostheses.

\section{Early and late prosthesis performance}

Prosthetic hemodynamic performances are reported in Figure 5. Mean trans-prosthetic gradient and effective orifice area remained stable over time in both groups (Table 5). Post-procedural mean gradient $\geq 20 \mathrm{mmHg}$ was present in $2.3 \%$ of $\mathrm{CV}$ group and $4.7 \%$ of ES group $(\mathrm{P}=0.14)$. The rate of $\geq 2+\mathrm{PVL}$ was higher in the $\mathrm{CV}$ compared to $\mathrm{ES}$ group $(11.5 \%$ vs. $1.2 \%, \mathrm{P}=0.01)$. Out of the 11 patients with a $\geq 2+$ PVL, 7 died within 48 months of follow-up. Among patients with trivial/mild PVL, no changes in leak severity were observed over time. Late prosthesis failure occurred in 4 patients (2.4\%), with no other case occurring in patients alive at 8 years. Structural valve deterioration was confirmed by CT scan or autopsy, whenever possible. One patient developed both increased trans-prosthetic gradients and $3+/ 4$ intra-prosthetic $\mathrm{AR}$ at 4 years and was treated with a valve-valve procedure; two patients had valve restenosis (mean gradients 38 and $43 \mathrm{mmHg}$, respectively) after 5 years; and one patient developed a severe intraprosthetic AR at 7 years; all these three patients were treated conservatively because of their high frailty status. Notably, late prosthesis failure occurred in patients with chronic kidney disease implanted with an ES THV through TA approach.

\section{Discussion}

The main findings of the current study analyzing long-term outcomes and prosthesis performance of the self-expandable $\mathrm{CV}$ and the balloon-expandable ES THV are: (I) clinical outcomes are favorable regardless of THV type, with most late deaths being non-cardiac; (II) besides some differences in acute results, both types of prostheses maintained a sustained and encouraging long-term hemodynamic performance in terms of mean trans-prosthetic gradient, effective orifice area and incidence of aortic regurgitation; 


\begin{tabular}{|c|c|c|c|c|}
\hline Age, year & $81[78-85]$ & $81[77-85]$ & 81 [79-85] & 0.87 \\
\hline Male, n (\%) & 70 (40.9) & $41(47.1)$ & $29(34.5)$ & 0.09 \\
\hline BMI $\left(\mathrm{kg} / \mathrm{m}^{2}\right)$ & $25.8 \pm 4.2$ & $25.8 \pm 4.3$ & $25.8 \pm 4.1$ & 1 \\
\hline Logistic EuroSCORE (\%) & 17.8 (12.7-27.9) & $17.8(12.1-31.8)$ & $18.1(12.9-27.5)$ & 0.59 \\
\hline Hypertension, n (\%) & $153(89.5)$ & 78 (89.7) & 75 (89.3) & 0.94 \\
\hline Dyslipidemia, n (\%) & $92(53.8)$ & $42(48.3)$ & $50(59.5)$ & 0.14 \\
\hline Smoking history, n (\%) & $36(21.1)$ & $15(17.2)$ & $21(25.0)$ & 0.21 \\
\hline Previous MI, n (\%) & $29(17.0)$ & $21(24.1)$ & $8(9.5)$ & 0.01 \\
\hline Previous $\mathrm{PCl}, \mathrm{n}(\%)$ & $53(31.0)$ & $28(32.2)$ & $25(29.8)$ & 0.73 \\
\hline Previous CABG, n (\%) & $27(15.8)$ & $17(19.5)$ & $10(11.9)$ & 0.17 \\
\hline Previous CHF, n (\%) & $85(49.7)$ & $43(49.4)$ & $42(50.0)$ & 0.94 \\
\hline Previous BAV, n (\%) & $4(2.3)$ & $4(4.6)$ & $0(0.0)$ & 0.12 \\
\hline PVD, n (\%) & 59 (34.5) & $34(39.1)$ & $25(29.8)$ & 0.2 \\
\hline PCA, n (\%) & $23(13.5)$ & $14(16.1)$ & $9(10.7)$ & 0.3 \\
\hline COPD, n (\%) & 47 (27.5) & $21(24.1)$ & 26 (31.0) & 0.32 \\
\hline IV & $14(8.2)$ & $7(8.0)$ & $7(8.3)$ & \\
\hline \multicolumn{5}{|l|}{ Angina CCS class, $n(\%)$} \\
\hline 0 & $118(69.0)$ & $56(64.4)$ & 62 (73.8) & 0.22 \\
\hline 1 & $2(1.2)$ & $2(2.3)$ & $0(0.0)$ & \\
\hline 2 & 17 (9.9) & $7(8.1)$ & 10 (11.9) & \\
\hline 3 & $22(12.9)$ & $14(16.1)$ & $8(9.5)$ & \\
\hline 4 & $12(7.0)$ & $8(9.2)$ & $4(4.8)$ & \\
\hline Syncope, n (\%) & 34 (19.9) & $15(17.2)$ & 19 (22.6) & 0.38 \\
\hline \multicolumn{5}{|c|}{$\begin{array}{l}\text { Data are expressed as absolute values and percentages, mean } \pm \mathrm{SD} \text {, or median }\left(25^{\text {th }}-75^{\text {th }} \text { percentile). CV, CoreValve; ES, Edwards }\right. \\
\text { SAPIEN; BMI, body mass index; CKD, Chronic Kidney disease; AF, atrial fibrillation; CABG, coronary artery bypass graft; COPD, chronic } \\
\text { obstructive pulmonary disease; MI, myocardial infarction; PCA, previous cerebrovascular accident; NYHA, New York Heart Association; } \\
\text { CCS, Canadian Cardiovascular Society; CHF, congestive heart failure; BAV, balloon aortic valvuloplasty; PCI, percutaneous coronary } \\
\text { intervention; PVD, peripheral vascular disease; STS, Society of Thoracic Surgeons. }\end{array}$} \\
\hline
\end{tabular}


Table 2 Baseline transthoracic echocardiography

\begin{tabular}{lllll}
\hline Variable & Total $(n=171)$ & CV group $(n=87)$ & ES group $(n=84)$ & $P$ \\
\hline AVA, $\mathrm{cm}^{2}$ & $0.78 \pm 0.20$ & $0.81 \pm 0.21$ & $0.75 \pm 0.19$ & 0.04 \\
\hline AVAi, $\mathrm{cm}^{2} / \mathrm{m}^{2}$ & $0.45 \pm 0.11$ & $0.47 \pm 0.12$ & $0.44 \pm 0.10$ & 0.05 \\
\hline Aortic MG, $\mathrm{mmHg}$ & $44[34-54]$ & $43[32-54]$ & $44.5[37.5-54]$ & 0.22 \\
\hline Aortic $\mathrm{PG}, \mathrm{mmHg}$ & $73[60-86]$ & $73.5[56-91]$ & $72[62-85]$ & 0.74 \\
\hline LVEF, \% & $56.5[48-63]$ & $53[41-62]$ & $58[52-64]$ & 0.01 \\
\hline EDV, $\mathrm{mL} / \mathrm{m}^{2}$ & $65[52-78]$ & $70[56-92]$ & $58[47-72]$ & $<0.001$ \\
\hline MR $\geq 2, \mathrm{n}(\%)$ & $42(24.6)$ & $20(23.0)$ & $22(26.2)$ & 0.63 \\
\hline AR $\geq 2, \mathrm{n}(\%)$ & $38(22.2)$ & $20(23.0)$ & $18(21.4)$ & 0.81 \\
\hline
\end{tabular}

Data are expressed as mean \pm SD or median $\left[25^{\text {th }}-75^{\text {th }}\right.$ percentile]. AVA, aortic valve area; AVAi, aortic valve area indexed; MG, mean gradient; PG, peak gradient; LVEF, left ventricular ejection fraction; EDV, end diastolic volume; MR, mitral regurgitation; AR, aortic regurgitation.

Table 3 Procedural characteristics and outcomes

\begin{tabular}{|c|c|c|c|c|}
\hline Procedural characteristic & Total $(n=171)$ & CV group $(n=87)$ & ES group $(n=84)$ & $\mathrm{P}$ \\
\hline \multicolumn{5}{|l|}{ Access, n (\%) } \\
\hline Transfemoral & $117(68.4)$ & $82(94.2)$ & $35(41.7)$ & $<0.001$ \\
\hline Tran-subclavian & $5(2.9)$ & $5(5.8)$ & - & \\
\hline Transapical & $49(28.7)$ & - & 49 (58.3) & \\
\hline Prosthesis post-dilatation, $\mathrm{n}(\%)$ & $30(17.5)$ & $27(31.0)$ & $3(3.6)$ & $<0.001$ \\
\hline Valve-in-valve, n (\%) & $3(1.8)$ & $2(2.3)$ & $1(1.2)$ & 1 \\
\hline \multicolumn{5}{|l|}{ Prosthesis diameter, n (\%) } \\
\hline 23-mm & $37(21.6)$ & $0(0)$ & $37(44.1)$ & $<0.001$ \\
\hline Hemodynamic success, n (\%) & $166(97.1)$ & $84(96.6)$ & $82(97.6)$ & 1 \\
\hline Device success (VARC 2), n (\%) & $162(94.7)$ & $82(94.3)$ & $80(95.2)$ & 1 \\
\hline Procedural mortality, n (\%) & $3(1.8)$ & $2(2.3)$ & $1(1.2)$ & 1 \\
\hline Cardiogenic shock, n (\%) & $4(2.3)$ & $1(1.2)$ & $3(3.6)$ & 0.36 \\
\hline Intra procedural AV block, n (\%) & $17(9.9)$ & $15(17.2)$ & $2(2.4)$ & 0.001 \\
\hline
\end{tabular}

Data are expressed as absolute values and percentages, or mean \pm SD. VARC, Valve Academic Research Consortium; AV, atrioventricular.

(III) late prosthesis failure rate was under 3\%.

Mid-term clinical outcomes after TAVR are reported to be favorable (23), but follow-up data over 3 years are scant, particularly those regarding "real world" populations included in registries $(10,24,25)$. In our study, the overall 5 -year survival rate was $44.9 \%$, with no difference between valve types. To note, $78.3 \%$ of the 5 -year observed total deaths were non-cardiac in origin, reflecting the relevant 


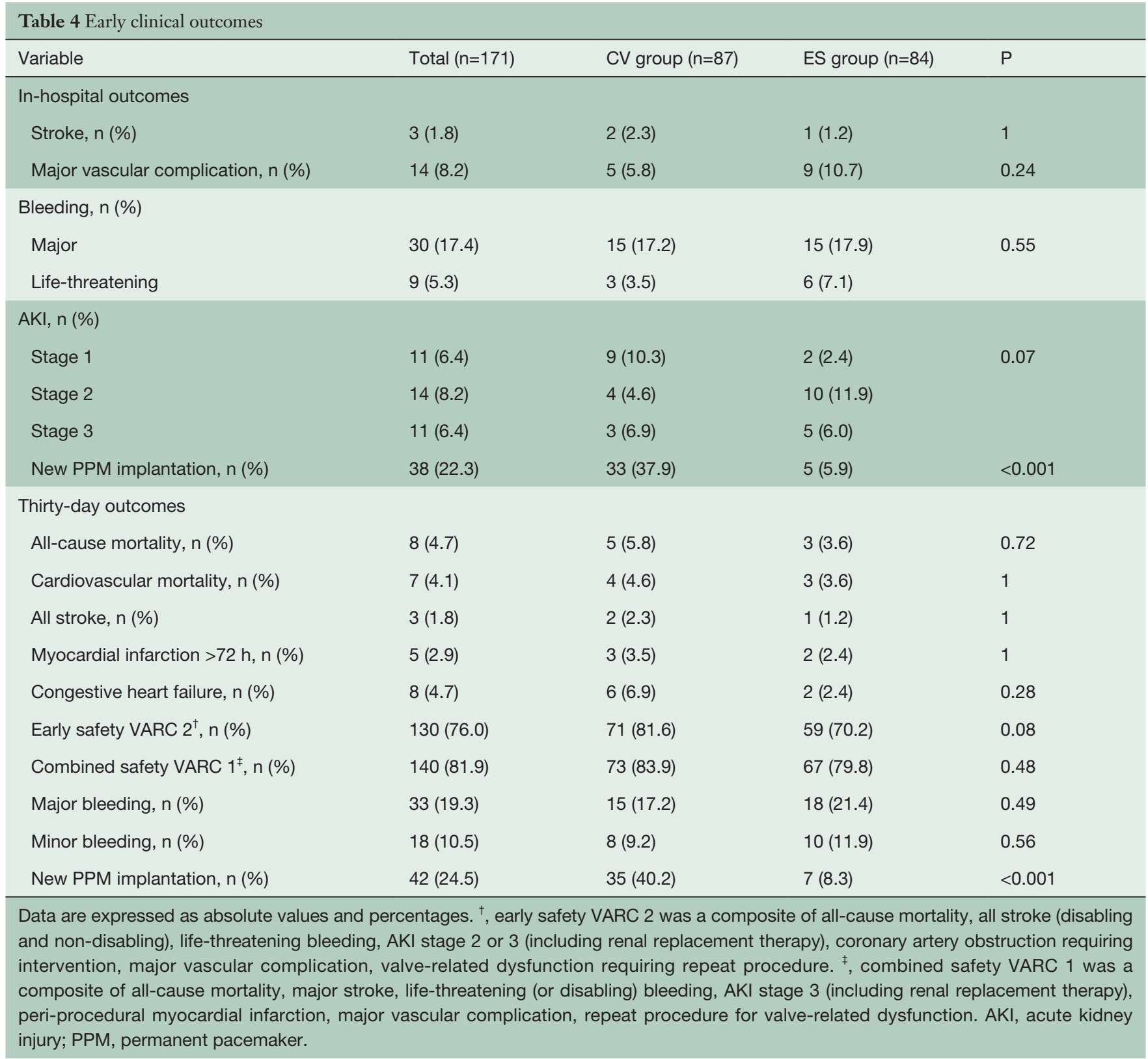

prognostic impact of comorbidities in this prohibitive/ high-risk population. Similar results were observed in the 5 -year analysis of the PARTNER 1 trial, in which over $2 / 3$ of deaths were non-cardiovascular (8). Notably, our TAVR cohort 8-year survival rate $(24.5 \%)$ was lower compared to the 8 -year survival of the 81 years old general Italian population (53\%, http://dati.istat.it), but comparable with long-term survival after surgical aortic valve replacement in a population aged $\geq 80$ years $(26,27)$. Regarding functional status, over $90 \%$ of our patients remained in NYHA class I-
II during the whole follow-up period. Less than $15 \%$ of our population was re-hospitalized for CHF, which was associated in nearly half of the patients with the presence of severe MR, consistent with previous reports in the literature (11).

Our study is the first reporting on direct comparison between CV and ES THV hemodynamics at follow-up longer than 3 years, with previous studies focusing only on early and mid-term clinical outcomes $(12,23,28-30)$. Based on our results, the implantation of both valves resulted in a significant reduction of mean aortic gradient, which 


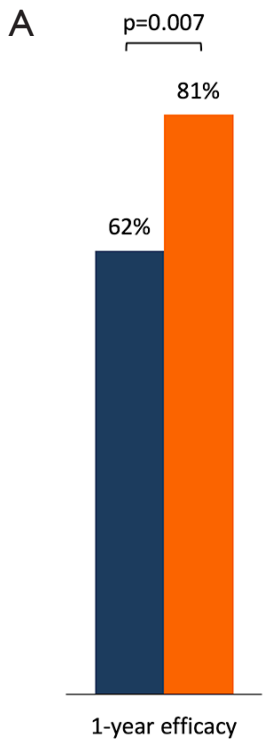

B

- CoreValve Edwards

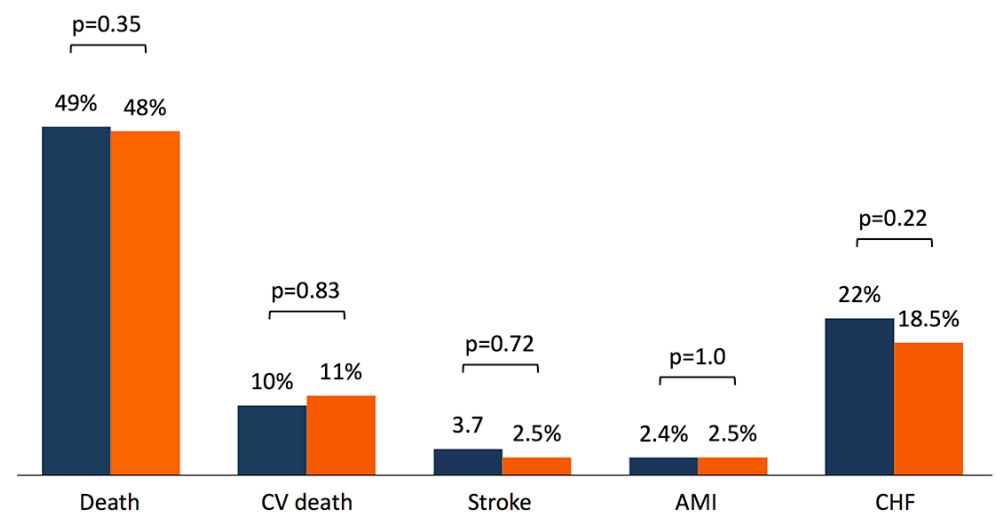

Figure 2 Clinical outcomes. (A) Clinical efficacy at 1 year; (B) clinical outcomes at 5 years. CoreValve group was represented by blue bars, Edwards by orange bars. CV, CoreValve; AMI, acute myocardial infarction; CHF, congestive heart failure.

\begin{tabular}{|c|c|c|c|c|}
\hline Variable & Total & CV group & ES group & $\mathrm{P}$ \\
\hline Early performance & $n=171$ & $\mathrm{n}=87$ & $\mathrm{n}=84$ & \\
\hline Aortic MG, mmHg & 10 [8-12] & 9 [7-12] & $10[8.5-13]$ & 0.04 \\
\hline AVA, $\mathrm{cm}^{2}$ & $1.89(1.65-2.10)$ & $1.92(1.74-2.18)$ & $1.80(1.53-1.98)$ & 0.01 \\
\hline AVAi, $\mathrm{cm}^{2} / \mathrm{m}^{2}$ & $1.08(0.95-1.28)$ & $1.14(0.99-1.35)$ & $1.03(0.89-1.15)$ & 0.01 \\
\hline$P V L \geq 2, n(\%)$ & $11(6.4)$ & $10(11.5)$ & $1(1.2)$ & 0.01 \\
\hline Five-year performance & $n=43$ & $n=24$ & $n=19$ & \\
\hline Aortic MG, mmHg & $10.5[8-31]$ & 8 [3-31] & 13 [5-25] & 0.11 \\
\hline AVA, $\mathrm{cm}^{2}$ & $1.73(0.9-2.5)$ & $1.73(1.07-2.1)$ & $1.73(0.9-2.5)$ & 1 \\
\hline AVAi, $\mathrm{cm}^{2} / \mathrm{m}^{2}$ & $1(0.5-1.61)$ & $1(0.5-1.61)$ & $1(0.5-1.48)$ & 1 \\
\hline$P V L \geq 2, n(\%)$ & $4(9.3)$ & $4(16.7)$ & $0(0)$ & 0.01 \\
\hline
\end{tabular}

remained low and stable over time. Patients receiving a $\mathrm{CV}$ seemed to have lower gradients and larger effective orifice area, but an initial higher rate of PVL, which seemed to remain stable over time. The latter finding was true also for the ES valve, confirming the PARTNER 1 trial results (31) and advocating stability of hemodynamic performance of both THV during the current follow-up period. Moreover, as shown by the 5 -year PARTNER I echocardiographic data, hemodynamic performance of the SAPIEN THV was stable throughout follow-up and similar to that of the surgical bioprosthesis (31). These results are particularly encouraging in the light of the significantly lower PVL rate observed with newer generation devices $(3,6)$, which will likely translate in improved long-term outcomes.

Toggweiler et al. (10) reported on clinical outcomes, valvular structural integrity, and hemodynamic changes 
A

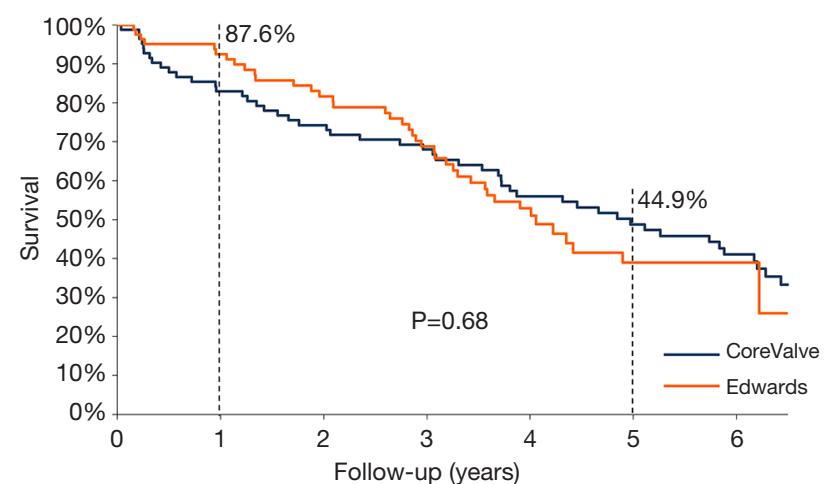

Number at risk

CoreValve 82

Edwards 81

$\begin{array}{ll}60 & 42 \\ 60 & 27\end{array}$

B

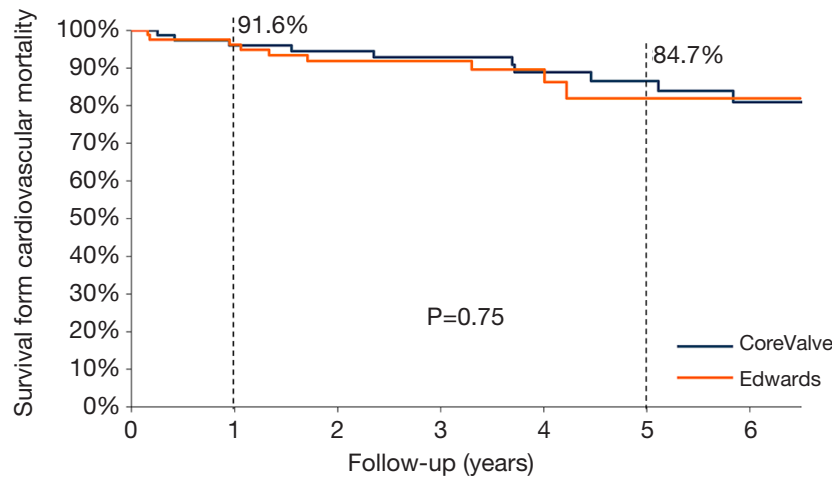

$\begin{array}{ll}\text { Number at risk } & \\ \text { CoreValve } & 82 \\ \text { Edwards } & 81\end{array}$

Figure 3 Kaplan-Meier analysis up to 6 years. Kaplan-Meier overall survival curves (A) and the rate of freedom from cardiovascular mortality (B) in the CoreValve group (blue line) and Edwards group (orange line).

\begin{tabular}{llll}
\hline \multicolumn{2}{l}{ Table 6 Multivariable predictors of mortality } & & P \\
\hline Variable & Hazard ratio & $95 \%$ confidence interval & $<0.0001$ \\
\hline PVL $\geq 2$ & 4.2 & $2.1-8.4$ & 0.006 \\
\hline Congestive heart failure & 1.8 & $1.2-2.7$ & 0.006 \\
\hline Pre-existing MR $\geq 3$ & 6.2 & $2.1-17.6$ & 0.02 \\
\hline COPD & 4.1 & $1.0-2.6$ & \\
\hline COPD, chronic obstructive pulmonary disease; MR, mitral regurgitation; PVL, paravalvular leak. &
\end{tabular}

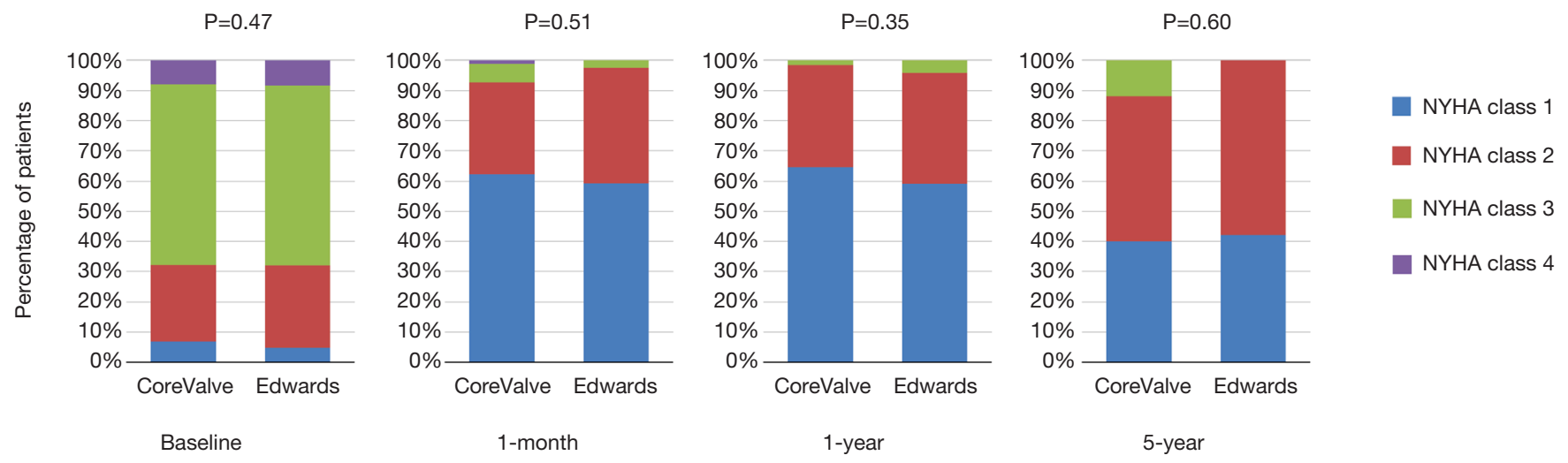

Figure 4 NYHA functional status. Longitudinal trend in NYHA functional status before and after TAVR through 5 years, according to type of implanted prosthesis. NYHA, New York Heart Association; TAVR, transcatheter aortic valve replacement. 
A

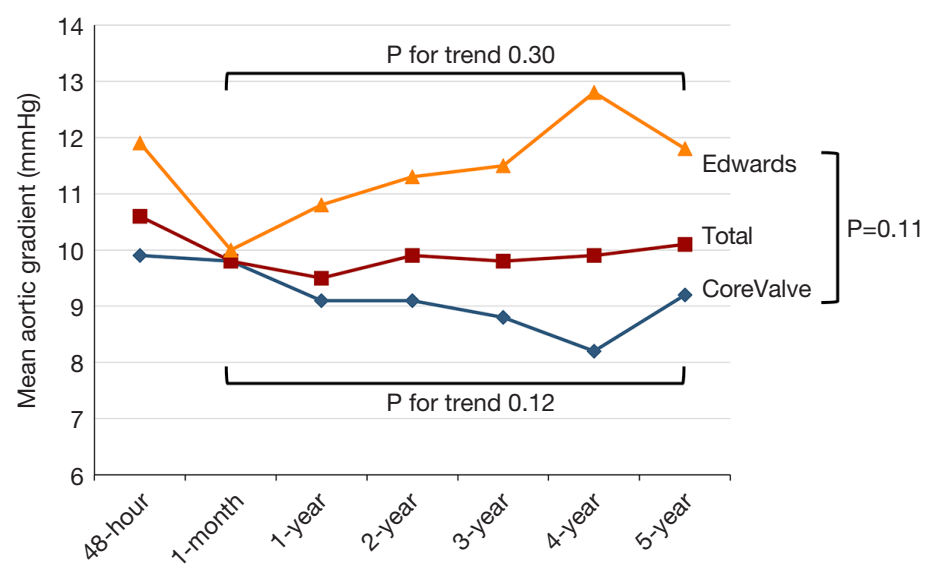

B

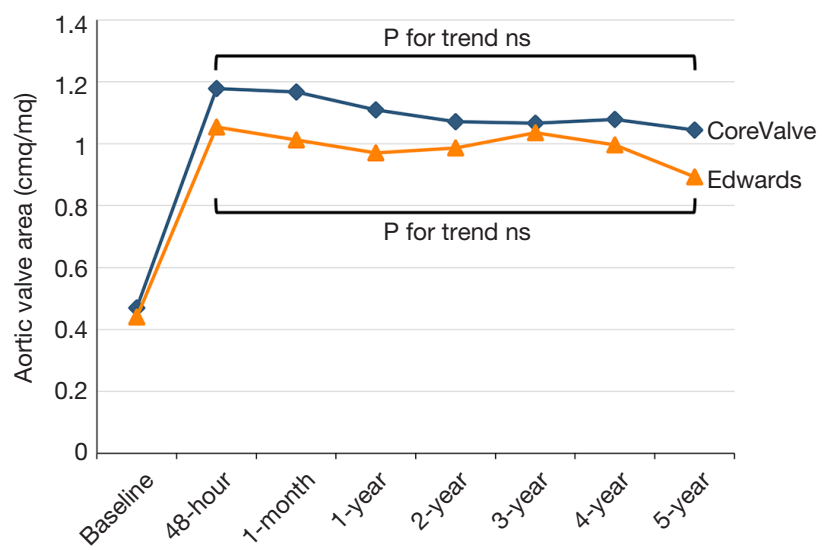

Figure 5 Valve hemodynamic performance over time. (A) Trend in mean aortic gradient from 48 h through 5 years; (B) trend in index aortic valve area from baseline through 5 years (6 patients excluded because of 48-h bioprosthesis dysfunction).

evaluated a median of 5 years after TAVR with a balloonexpandable valve. They observed moderate prosthetic valve failure only in $3.4 \%$ of patients without severe regurgitation or stenosis. Barbanti and colleagues (11) reported late prosthetic valve failure at 5 years in $1.4 \%$ of patients included in the CV registry. In our study, no clinically relevant prosthesis restenosis was observed at 3-year followup. Between 3 and 7 years of follow-up, we reported only 4 cases of late prosthetic valve failure (2.4\%).

\section{Limitations}

This is a single-center, observational study with a fairly limited number of patients. Larger studies are warranted to confirm these results and the lack of difference in longterm outcomes between different THVs. Clinical and echocardiographic outcomes were self-reported, with inherent limitations and potential bias. However, data were prospectively collected in a dedicated database as shown by the detailed availability of clinical and echocardiographic data. Patients included in this study represent the early phase of the TAVR program at our institution, which may have influenced patient selection and thus long-term outcome. The impact of different learning curves cannot be tested. Even so, no differences emerged between the two bioprostheses after the introduction of ES in 2009. Furthermore, since baseline CT was not available in all patients, we cannot exclude that the difference in postprocedural aortic gradients between CV and ES could have been influenced by different aortic valve dimension and calcium distribution. Notwithstanding, stability of hemodynamic performance over time was reassuring for both valves.

\section{Conclusions}

Our study demonstrated favorable outcomes at long-term follow-up after successful TAVR, independently from THV type. Prostheses hemodynamic performance was encouraging and sustained, with a late prosthesis failure rate lower than $3 \%$. Longer follow-up studies with newer generation devices are warranted before extending TAVR to lower risk and younger patients.

\section{Acknowledgements}

None.

\section{Footnote}

Conflicts of Interest: The authors have no conflicts of interest to declare.

\section{References}

1. Makkar RR, Fontana GP, Jilaihawi H, et al. Transcatheter aortic-valve replacement for inoperable severe aortic stenosis. N Engl J Med 2012;366:1696-704.

2. Kodali SK, Williams MR, Smith CR, et al. Two-year outcomes after transcatheter or surgical aortic-valve 
replacement. N Engl J Med 2012;366:1686-95.

3. Leon MB, Smith CR, Mack MJ, et al. Transcatheter or Surgical Aortic-Valve Replacement in Intermediate-Risk Patients. N Engl J Med 2016;374:1609-20.

4. Thourani VH, Kodali S, Makkar RR, et al. Transcatheter aortic valve replacement versus surgical valve replacement in intermediate-risk patients: a propensity score analysis. Lancet 2016;387:2218-25.

5. Rodés-Cabau J. Transcatheter aortic valve implantation: current and future approaches. Nat Rev Cardiol 2011;9:15-29.

6. Reardon MJ, Van Mieghem NM, Popma JJ, et al. Surgical or Transcatheter Aortic-Valve Replacement in IntermediateRisk Patients. N Engl J Med 2017;376:1321-31.

7. Salizzoni S, D'Onofrio A, Agrifoglio M, et al. Early and mid-term outcomes of 1904 patients undergoing transcatheter balloon-expandable valve implantation in Italy: results from the Italian Transcatheter BalloonExpandable Valve Implantation Registry (ITER). Eur J Cardiothorac Surg 2016;50:1139-48.

8. Mack MJ, Leon MB, Smith CR, et al. 5-year outcomes of transcatheter aortic valve replacement or surgical aortic valve replacement for high surgical risk patients with aortic stenosis (PARTNER 1): a randomised controlled trial. Lancet 2015;385:2477-84.

9. Kapadia SR, Leon MB, Makkar RR, et al. 5-year outcomes of transcatheter aortic valve replacement compared with standard treatment for patients with inoperable aortic stenosis (PARTNER 1): a randomised controlled trial. Lancet 2015;385:2485-91.

10. Toggweiler S, Humphries KH, Lee M, et al. 5-year outcome after transcatheter aortic valve implantation. J Am Coll Cardiol 2013;61:413-9.

11. Barbanti M, Petronio AS, Ettori F, et al. 5-Year Outcomes After Transcatheter Aortic Valve Implantation With CoreValve Prosthesis. JACC Cardiovasc Interv 2015;8:1084-91.

12. Duncan A, Ludman P, Banya W, et al. Long-term outcomes after transcatheter aortic valve replacement in high-risk patients with severe aortic stenosis: the U.K. Transcatheter Aortic Valve Implantation Registry. JACC Cardiovasc Interv 2015;8:645-53.

13. Fraccaro C, Buja G, Tarantini G, et al. Incidence, predictors, and outcome of conduction disorders after transcatheter self-expandable aortic valve implantation. Am J Cardiol 2011;107:747-54.

14. Gasparetto V, Fraccaro C, Tarantini G, et al. Safety and effectiveness of a selective strategy for coronary artery revascularization before transcatheter aortic valve implantation. Catheter Cardiovasc Interv 2013;81:376-83.

15. Tarantini G, Gasparetto V, Napodano M, et al.

Transcatheter aortic valve implantation and bleeding: focus on Valve Academic Research Consortium-2 classification. Int J Cardiol 2013;168:5001-3.

16. Nishimura RA, Otto CM, Bonow RO, et al. 2014 AHA/ ACC guideline for the management of patients with valvular heart disease: a report of the American College of Cardiology/American Heart Association Task Force on Practice Guidelines. J Thorac Cardiovasc Surg 2014;148:e1-132.

17. Vahanian A, Alfieri O, Andreotti F, et al. Guidelines on the management of valvular heart disease (version 2012): the Joint Task Force on the Management of Valvular Heart Disease of the European Society of Cardiology (ESC) and the European Association for Cardio-Thoracic Surgery (EACTS). Eur J Cardiothorac Surg 2012;42:S1-44.

18. Saffioti S, Burzotta F, Coluccia V, et al. Usefulness of EuroSCORE systems for risk stratification. J Cardiovasc Med (Hagerstown) 2015;16:90-9.

19. Shahian DM, He X, Jacobs JP, et al. The Society of Thoracic Surgeons Isolated Aortic Valve Replacement (AVR) Composite Score: a report of the STS Quality Measurement Task Force. Ann Thorac Surg 2012;94:2166-71.

20. Kappetein AP, Head SJ, Généreux P, et al. Updated standardized endpoint definitions for transcatheter aortic valve implantation: the Valve Academic Research Consortium-2 consensus document. J Am Coll Cardiol 2012;60:1438-54.

21. Lancellotti P, Tribouilloy C, Hagendorff A, et al. European Association of Echocardiography recommendations for the assessment of valvular regurgitation. Part 1: aortic and pulmonary regurgitation (native valve disease). Eur J Echocardiogr 2010;11:223-44.

22. Zoghbi WA, Chambers JB, Dumesnil JG, et al. Recommendations for evaluation of prosthetic valves with echocardiography and doppler ultrasound: a report From the American Society of Echocardiography's Guidelines and Standards Committee and the Task Force on Prosthetic Valves, developed in conjunction with the American College of Cardiology Cardiovascular Imaging Committee, Cardiac Imaging Committee of the American Heart Association, the European Association of Echocardiography, a registered branch of the European Society of Cardiology, the Japanese Society of Echocardiography and the Canadian Society of Echocardiography, endorsed by the American College 
of Cardiology Foundation, American Heart Association, European Association of Echocardiography, a registered branch of the European Society of Cardiology, the Japanese Society of Echocardiography, and Canadian Society of Echocardiography. J Am Soc Echocardiogr 2009;22:975-1014; quiz 1082-4.

23. Collas VM, Dubois C, Legrand V, et al. Midterm clinical outcome following Edwards SAPIEN or Medtronic Corevalve transcatheter aortic valve implantation (TAVI): Results of the Belgian TAVI registry. Catheter Cardiovasc Interv 2015;86:528-35.

24. Bouleti C, Himbert D, Iung B, et al. Long-term outcome after transcatheter aortic valve implantation. Heart 2015;101:936-42.

25. Schymik G, Würth A, Bramlage P, et al. Long-term results of transapical versus transfemoral TAVI in a real world population of 1000 patients with severe symptomatic aortic stenosis. Circ Cardiovasc Interv 2014;8.

26. Sharabiani MT, Fiorentino F, Angelini GD, et al. Longterm survival after surgical aortic valve replacement among patients over 65 years of age. Open heart 2016;3:e000338.

27. Brennan JM, Edwards FH, Zhao Y, et al. Long-term survival after aortic valve replacement among high-risk

Cite this article as: Tarantini G, Purita PA, D'Onofrio A, Fraccaro C, Frigo AC, D'Amico G, Fovino LN, Martin M, Cardaioli F, Badawy MR, Napodano M, Gerosa G, Iliceto S. Long-term outcomes and prosthesis performance after transcatheter aortic valve replacement: results of selfexpandable and balloon-expandable transcatheter heart valves. Ann Cardiothorac Surg 2017;6(5):473-483. doi: 10.21037/ acs.2017.08.02 elderly patients in the United States: insights from the Society of Thoracic Surgeons Adult Cardiac Surgery Database, 1991 to 2007. Circulation 2012;126:1621-9.

28. Chieffo A, Buchanan GL, Van Mieghem NM, et al. Transcatheter aortic valve implantation with the Edwards SAPIEN versus the Medtronic CoreValve Revalving system devices: a multicenter collaborative study: the PRAGMATIC Plus Initiative (Pooled-RotterdAmMilano-Toulouse In Collaboration). J Am Coll Cardiol 2013;61:830-6.

29. Sabaté M, Cánovas S, García E, et al. In-hospital and midterm predictors of mortality after transcatheter aortic valve implantation: data from the TAVI National Registry 20102011. Rev Esp Cardiol (Engl Ed) 2013;66:949-58.

30. Abdel-Wahab M, Mehilli J, Frerker C, et al. Comparison of balloon-expandable vs self-expandable valves in patients undergoing transcatheter aortic valve replacement: the CHOICE randomized clinical trial. JAMA 2014;311:1503-14.

31. Daubert MA, Weissman NJ, Hahn RT, et al. Long-Term Valve Performance of TAVR and SAVR: A Report From the PARTNER I Trial. JACC Cardiovasc Imaging 2016. [Epub ahead of print]. 